\title{
Penerapan Learning Management System Untuk Karyawan Perusahaan Menggunakan Mesin Turing
}

\section{Fahmi Ardiansyah", Sendi Permana², Windu Gata ${ }^{3}$, Eni Heni Hermaliani ${ }^{4}$, Laela Kurniawati $^{5}$}

\author{
1,2,3,4 Program Studi Ilmu Komputer, Universitas Nusa Mandiri, Jakarta. \\ ${ }^{5}$ Program Studi Sistem Informasi, Universitas Nusa Mandiri, Jakarta.
}
114207047@nusamandiri.ac.id, ${ }^{2} 14207003 @ n u s a m a n d i r i . a c . i d,{ }^{3}$ windu@nusamandiri.ac.id,

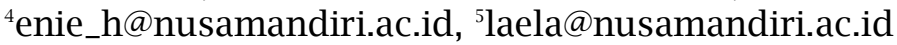

\begin{abstract}
In today's learning to find out more knowledge possessed by an employee in the company is quite a bit this can lead to from the company side not knowing much about the knowledge background possessed by an employee. On the employee side, in the absence of self-development facilities from the company, one day employees may leave the company because of the lack of company facilities. Therefore, one of the efforts to improve the quality of the quality of employees is to implement a Learning Management System (LMS) application for employees in a company using the Turing machine model. So with the construction of this application, it is hoped that employees can learn easily and help companies find out how far the potential knowledge of each employee is with this report being useful as an assessment for employees. This application is equipped with an Application Programming Interface (API) integration feature for employee data, to be able to read the data, a Turing machine model method is needed to read and write to the database so that the steps will be illustrated in the transition diagram from the class creation stage, API synchronization, to the employee was successfully enrolled in the learning class. With the use of the Turing machine model method, it is expected to produce effective and efficient LMS applications for employees and companies.
\end{abstract}

Keywords: Learning Management System, Turing Machine, Website, API

Abstrak: Dimasa kini pembelajaran untuk mengetahui pengetahuan yang lebih yang dimiliki oleh suatu karyawan dalam perusahaan cukup sedikit hal ini dapat menimbulkan dari sisi perusahaan tidak mengetahui banyak hal tentang latar belakang ilmu pengetahuan yang dimiliki oleh seorang karyawan. Disisi karyawan dengan tidak adanya fasilitas pengembangan diri dari perusahaan suatu saat karyawan bisa saja keluar dari perusahaan tersebut karna minimnya fasilitas perusahaan. Oleh karena itu salah satu upaya untuk meningkatkan kualitas dari mutu karyawan adalah dengan menerapkan aplikasi Learning Management System (LMS) bagi karyawan dalam suatu perusahaan menggunakan model mesin turing. Sehingga dengan dibangunnya aplikasi ini diharapkan karyawan dapat belajar dengan mudah dan membantu perusahaan mengetahui seberapa jauh potensi ilmu yang dimiliki masing-masing dari karyawan dengan laporan ini berguna sebagai penilaian bagi karyawan. Aplikasi ini dilengkapi dengan fitur integrasi Application Programming Interface (API) data karyawan, untuk dapat membaca data tersebut dibutuhkan metode model mesin turing untuk membaca dan menulis ke dalam database sehingga langkah - langkahnya akan digambarkan pada diagram transisi dari tahap pembuatan kelas, sinkornasi API, hingga karyawan tersebut berhasil didaftarkan dalam kelas pembelajaran. Dengan penggunaan metode model mesin turing diharapkan menghasilkan aplikasi LMS yang efektif dan efisien bagi karyawan dan perusahaan.

Kata kunci: Sistem Manajemen Pembelajaran, Mesin Turing, Website, API 


\section{Pendahuluan}

Seiring dengan kemajuan teknologi informasi dan komunikasi saat ini, ilmu pengetahuan itu sangat diperlukan. Karena ilmu pengetahuan itu penting dalam terbentuknya perilaku terbuka (Donsu, 2017) dimiliki oleh seorang manusia yang dapat di implementasikan dikemudian hari berdasarkan dari pengalaman, studi dan percobaan yang telah dilakukan dipakai untuk menentukan hakikat prinsip tentang hak yang sedang dipelajari. Dimasa kini pembelajaran untuk mengetahui pengetahuan yang lebih yang dimiliki oleh suatu karyawan dalam perusahaan cukup sedikit (Harijanto et al., 2017) hal ini dapat menimbulkan dari sisi perusahaan tidak mengetahui banyak hal tentang latar belakang ilmu pengetahuan yang dimiliki oleh seorang karyawan. Disisi karyawan dengan tidak adanya fasilitas pengembangan diri dari perusahaan karna minimnya fasilitas perusahaan. Kondisi seperti ini akan berakibat buruk, baik dari sisi perusahaan maupun karyawan. Dalam rangka meningkatkan mutu dari perusahaan dan sumber daya manusia yang dimiliki agar berkompeten strategi yang harus diterapkaan oleh perusahaan adalah meningkatkan fasilitas pembelajaran bagi karyawannya. Salah satu upaya untuk meningkatkan kualitas dari mutu karyawan adalah dengan menerapkan aplikasi Learning Management System (LMS) bagi karyawan dalam perusahaan menggunkan mesin turing. LMS adalah suatu aplikasi perangkat lunak untuk keperluan kegiatan proses belajar mengajar dan kegiatan yang terhubung secara online maupun offline (Sanova, 2018). LMS merupakan suatu sistem pembelajaran yang mencakup dalam bidang teknologi informasi dengan memanfaatkan aplikasi website yang dapat diakses melalui internet yang memungkinkan pembelajaran melalui computer (Siregar et al., 2018) (Aidah, 2019). Pembelajaran berbasis LMS dikembangkan secara dinamis yang berisi kemasan materi - materi dalam bentuk multimedia (text, animasi, video dan sound). Didalam LMS nantinya terdapat catatan-catatan berbagai kegiatan yang dilakukan karyawan. Permasalahannya jika menelusuri data karyawan dilakukan secara manual akan mengahabiskan waktu dan menyita banyak aktifitas (Affandi, 2018). Karena tiap waktu data karyawan yang mengikuti pembelajaran semakin bertambah sehingga untuk menganalisa tiap - tiap karyawan ter-update sulit dilakukan. Untuk dapat melakukan analisis lebih lanjut terhadap data karyawan tersebut perlu dilakukan pencatatan ulang ke dalam sebuah database. Pencatatan data kedalam database dapat dilakukan dengan memanfaatkan model otomata (Affandi, 2018), yaitu sebuah model mesin abstrak yang mempunyai input dan output diskrit dari permasalahan yang sedang dihadapi. Model yang dapat dipakai adalah model mesin turing.

Menurut (Sulistyanto \& Pulungan, 2014) menyatakan pada penelitiannya mesin turing adalah model komputasi yang berfungsi sebagai ilustrasi perhitungan atau komputasi matematis, model ini tetap diterima dikalangan ilmu komputer sebagai model komputer yang sesuai untuk menentukan apakah suatu fungsi dapat diselesaikan oleh komputer atau tidak.

PT. Infomedia Nusantara yang beralamat di jalan RS. Fatmawati saat ini belum diterapkan aplikasi pengembangan ilmu pengetahuan dan kemampuan yang dimiliki perusahaan terhadap karyawan. Solusi yang dapat dibuat dari masalah tersebut dengan membuat media pembelajaran dan pengasahan terhadap kemampuan suatu karyawan untuk mengembangkan keahlian atau skill karyawan, dari sisi perusahaan dapat mengetahui potensi lebih yang dimiliki oleh tiap - tiap karyawannya. Penerapan aplikasi ini dibutuhkan integrasi API data karyawan, untuk dapat membaca data 
tersebut dibutuhkan metode model mesin turing untuk membaca dan menulis ke dalam database sehingga langkah - langkahnya akan digambarkan pada diagram transisi dari tahap pembuatan kelas, sinkornasi API, hingga karyawan tersebut berhasil didaftarkan dalam kelas pembelajaran. Dengan penggunaan metode model mesin turing diharapkan menghasilkan aplikasi LMS yang efektif dan efisien bagi karyawan dan perusahaan.

\section{Metode}

Model System Development Life Cycle (SDLC) sering juga disebut model air terjun (waterfall) menyediakan pendekatan alur diterapkan dalam penelitian ini. Daur hidup perangkat lunak secara sekuensial atau terurut dimulai dari analisa masalah dengan dibarengi pengumpulan data, desain, pengkodean, pengujian, dan tahap pendukung (Rosa \& Shalahuddin, 2018). Langkah - langkah penelitian yang dilakukan pada gambar 1, meliputi:

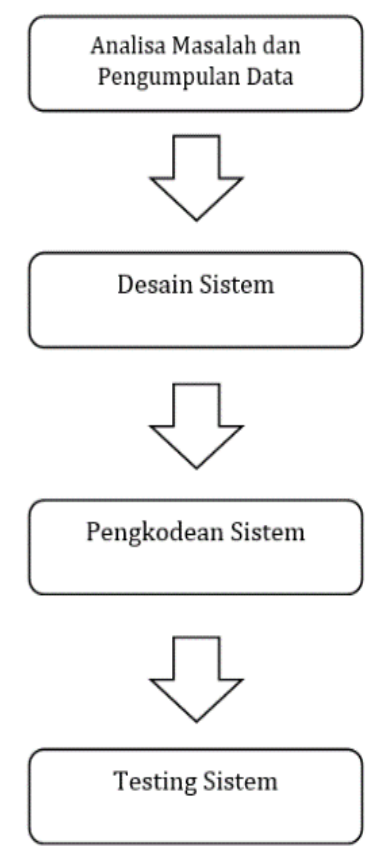

Gambar 1. System Development Life Cycle (SDLC)
1) Analisa masalah dan pengumpulan data, terdiri dari:
a) Menganalisa masalah yang terjadi pada PT. Infomedia Nusantara.
b) Menyusun daftar permasalahan yang dihadapi.
c) Mengumpulkan data yang terkait.
d) Menganalisis data yang diperlukan.

2) Mendesain alur sistem pengontrolan, terdiri dari:
a) Menentukan dan merancang model otomata yang digunakan untuk memecahkan beberapa masalah yang telah disusun.
b) Mendesain sistem menggunakan metode UML (Unified Modeling Language).
3) Pengkodingan program
4) Testing

\section{Hasil}

Analisa Masalah dan Pengumpulan Data

Program pembelajaran secara daring untuk karyawan PT. Infomedia Nusantara dengan menerapkan website yang akan dijalankan di browser dengan tujuan memberikan interaksi antarmuka (Siregar et al., 2018) LMS bagi karyawannya. Oleh karena itu pada penelitian ini kami membuat Flowchart untuk memberikan gambaran siklus pembelajaran LMS pada PT. Infomedia Nusantara, dengan menggambarkan bagaimana alur proses pembelajaran peserta belajar LMS pada PT. Infomedia Nusantara akan digambarkan dalam Flowchart yang dapat dilihat pada gambar 2 . 


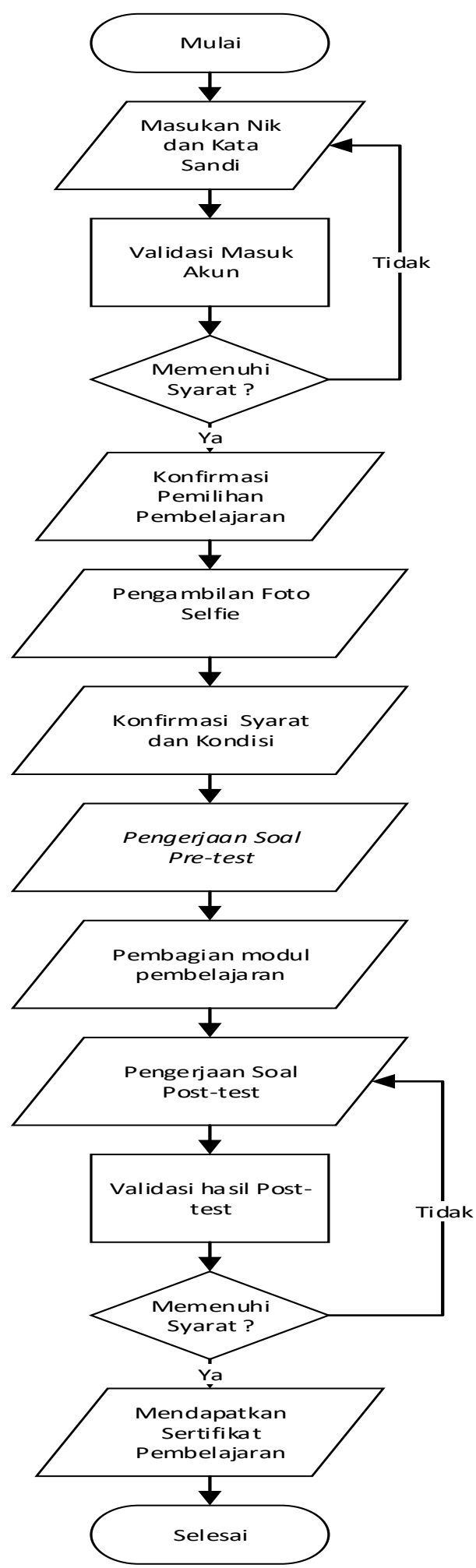

Gambar 2 Flowchart Konsep Siklus Pembelajaran

Pada gambar 2 menggambarkan proses pembelajaran untuk karyawan pada PT. Infomedia Nusantara dari proses pertama user masuk kedalam akunnya masing - masing user dapat melihat kelas yang harus dia ikuti dan harus mengkonfirmasi mengikuti kelas pembelajaran tersebut, selanjutnya peserta akan diharuskan mengambil gambar swafoto sebelum mengikuti kelas,tahap berikutnya peserta akan menemui syarat dan ketentuan dalam kelas pembelajaran yang diikuti, tahap berikutnya peserta akan diberikan soal pretest, tahap berikutnya peserta akan diberikan module pembelajaran baik berupa gambar, presentasi, video, maupun hanya suara, selanjutnya karyawan mengerjakan soal post-test, dari tahap ini merupakan tahap terakhir dimana nilai akan dikalkulasi sesuai dengan pengerjaan tiap - tiap karyawan yang nantinya ada karyawan yang lulus kelas pembelajaran akan mendapatkan sertifikat kelulusan dari kelas yang dipelajarinya tersebut. Jika gagal akan diberikan kesempatan sebanyak ketentuan yang berlaku namun jika tetap gagal peserta tidak dapat sertifikat tersebut.

Kegiatan pengumpulan data digunakan untuk mengumpulkan datadata yang diperlukan dalam penelitian ini melalui, cara: 1) Wawancara penulisan ini,untuk mendapatkan informasi secara lengkap maka penulis melakukan suatu metode suatu tanya jawab mengenai semua kegiatan yang berhubungan dengan konsep penerapan LMS yang akan diterapkan di PT. Infomedia Nusantara, 2) Pengamatan dilakukan langsung terhadap kegiatan yang ada di perusahaan tersebut di bagian human resource khususnya dalam mengelola data - data karyawan yang berkaitan dengan penerapan LMS yang akan diterapkan di PT. Infomedia Nusantara, 3) Studi Pustaka mengumpulkan data-data primer dan data sekunder untuk data sekunder seperti data karyawan, riwayat pekerjaan, data pelatihan yang pernah diikuti,dan data riwayat hidup 
karyawan. Untuk data sekunder seperti di buku-buku, artikel, jurnal, internet dan file-file yang tentunya berhubungan dengan penulisan ini untuk mendapatkan tambahan informasi.

\section{Desain Sistem}

Desain sistem dibuat mengikuti desain flowchart yang telah dibuat sebelumnya, berdasarkan desain tersebut dibutuhkan beberapa alat untuk pengembangan perangkat lunak yaitu yang mempunyai hardware minimal menggunakan processor core i3, RAM 4 GB, monitor, keyboard, mouse, speaker, sedangkan software yang dibutuhkan menggunakan sistem operasi minimal windows 7 atau versi atasnya.

Selanjutnya ada beberapa perangkat lunak yang dibutuhkan antara lain LMS ini akan dibangun menggunakan bahasa pemrograman PHP dengan framework codeigniter (Hidayatullah \& Jauhari, 2017), PHP merupakan hypertext preprocessor yang merupakan scripting yang tempat pengolahannya berada di server(Yani \& Saputra, 2018). Selain itu juga sudah disediakan REST Server yang dapat memudahkan pembuatan aplikasi(Setiyawan et al., 2019) dengan bahasa pemrograman PHP dan menggunakan database Mysql yang merupakan database server yang bersifat multi user dan multi-threaded sehingga data tersebut dapat dimanipulasi, diambil dan dicari secara cepat (Risdiansyah, 2017)(Nurmalasari et al., 2019)(Hidayat, 2017)(Hidayat, 2017). Karena Rest Server sudah tersedia dibagian human resource data tersebut tinggal dikelola kedalam database LMS yang akan dibangun, berikut endpoint dan response yang diberikan:
Tabel 1. endpoint dan response

\begin{tabular}{|c|c|c|c|}
\hline No & Endpoint & Method & Response \\
\hline 1. & $\begin{array}{c}\text { /api/unit/b } \\
\text { y_level/1 }\end{array}$ & Get & $\begin{array}{c}\text { Mengembali } \\
\text { kan data } \\
\text { seluruh } \\
\text { direktorat } \\
\text { dalam } \\
\text { bentuk JSON }\end{array}$ \\
\hline 2 & $\begin{array}{c}\text { /api/unit/b } \\
\text { y_level/2 }\end{array}$ & Get & $\begin{array}{l}\text { Mengembali } \\
\text { kan data } \\
\text { seluruh } \\
\text { divisi dalam } \\
\text { bentuk JSON }\end{array}$ \\
\hline 3 & $\begin{array}{c}\text { /api/unit/b } \\
\text { y_level/3 }\end{array}$ & Get & $\begin{array}{l}\text { Mengembali } \\
\text { kan data } \\
\text { seluruh } \\
\text { departemen } \\
\text { dalam } \\
\text { bentuk JSON }\end{array}$ \\
\hline 4 & $\begin{array}{c}\text { /api/unit/b } \\
\text { y_level/4 }\end{array}$ & Get & $\begin{array}{l}\text { Mengembali } \\
\text { kan data } \\
\text { seluruh } \\
\text { posisi dalam } \\
\text { bentuk JSON }\end{array}$ \\
\hline 5. & $\begin{array}{c}\text { /api/unit/b } \\
\text { y_level/5 }\end{array}$ & Get & $\begin{array}{l}\text { Mengembali } \\
\text { kan data } \\
\text { seluruh } \\
\text { layanan } \\
\text { dalam } \\
\text { bentuk JSON }\end{array}$ \\
\hline 6. & $\begin{array}{c}\text { /api/emplo } \\
\text { yee/data/by } \\
\text { _id/<organi } \\
\text { sasi_id> }\end{array}$ & Get & $\begin{array}{c}\text { Mengembali } \\
\text { kan data } \\
\text { seluruh } \\
\text { karyawan } \\
\text { sesui } \\
\text { dengan kode } \\
\text { organisasi } \\
\text { dalam } \\
\text { bentuk JSON }\end{array}$ \\
\hline
\end{tabular}

Agar proses pembuatan konsep aplikasi ini berjalan seperti yang diharapkan, maka perlu dilakukan pembuatan alur proses pembelelajaran pada LMS, sebagai berikut:

1) Membuat judul kelas pembelajaran

2) Memilih jenis soal pre-test

3) Memilih modul pembelajaran 
4) Memilih jenis soal post-test

5) Memilih jenis sertifikat

6) Mensinkornasi data karyawan

7) Mendaftarkan karyawan dalam suatu kelas pembelajaran

8) Peserta mendapatkan email berupa NIK dan kata sandi untuk masuk akun masing-masing

9) Peserta masuk akun masing -masing

10) Peserta konfirmasi pembelajaran

11)Peserta pengambilan foto selfie

12) Peserta menyetujui syarat dan ketentuan

13)Peserta mengerjakan soal pre-test

14)Peserta mendapatkan modul pembelajaran

15) Peserta mengerjakan soal post-test

16)Peserta mendapatkan sertifikat pembelajaran

Alur tersebut digunakan oleh mesin turing untuk menggerakkan head ke kiri atau ke kanan dari sel-sel penyimpanan dari 7 tumpukan (Affandi et al., 2019) (Sulistyanto \& Pulungan, 2014) setelah menerima data dari database. Untuk mempermudah pembuatan alur program, maka diperlukan teknik agar dapat diproleh proses proses pergerakan alur yang telah di jelaskan diatas. Berikut graph mesin turing yang menunjukan proses alur aplikasi:

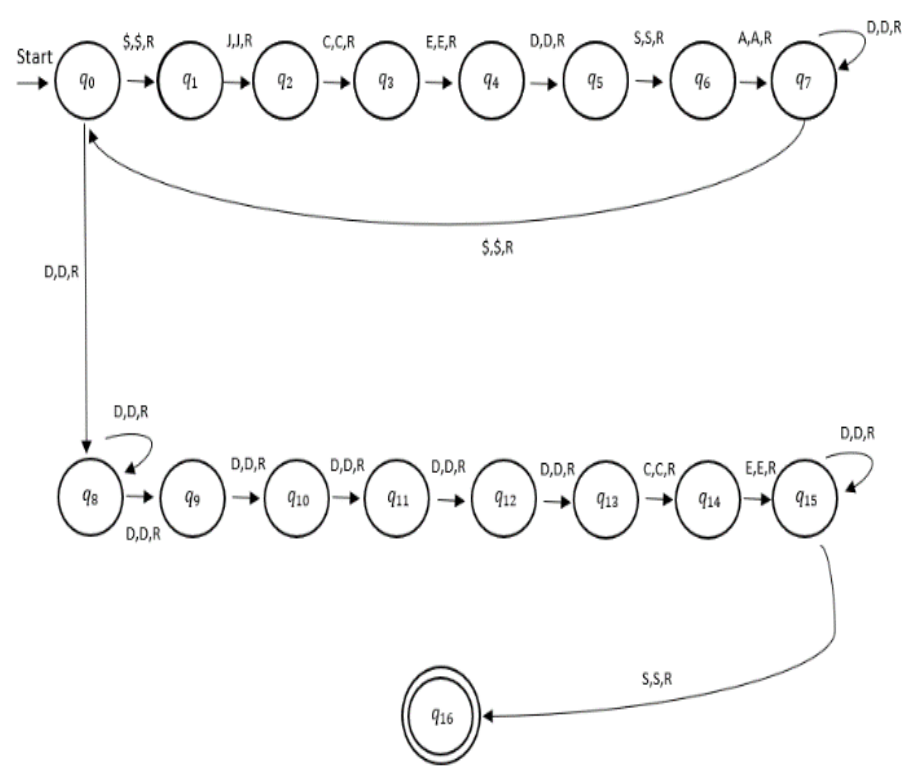

Gambar 3 Diagram Transisi
Berdasarkan diagram transisi diatas, berikut keterangan graph tersebut:

State: $\{\mathrm{q} 0, \mathrm{q} 1, \mathrm{q} 2, \mathrm{q} 3, \mathrm{q} 4, \mathrm{q} 5, \mathrm{q} 6, \mathrm{q} 7$, q8, q9, q10, q11, q12, q13, q14, q15, q16\}

State Awal: $\{\mathrm{q} 0\}$

State penerima: $\{\mathrm{q} 16\}$

String Input:

\$: String hampa

J: Judul Kelas

C: Soal Pre-test

D: Soal Post-test

E: Modul Pembelajaran

S: Sertifikat

A: API data karyawan

D: Data karyawan

R: Pergerakan (right)

Pada diagram state ini memiliki beberapa transisi, berikut penjelasan tentang fungsi transisi yang ada pada tabel fungsi transisis diatas, sebagai berikut:

$\mathrm{q} 0=$ State awal (initial state)

$\mathrm{q} 1=$ Membuat judul kelas pembelajaran

q2 = Memilih jenis soal pre-test

q3 = Memilih modul pembelajaran

$\mathrm{q} 4=$ Memilih jenis soal post-test

q5 $=$ Memilih jenis sertifikat

q6 = Mensinkornasi data karyawan

q7 = Mendaftarkan karyawan dalam suatu kelas pembelajaran

q8 = Peserta mendapatkan email berupa NIK dan kata sandi untuk masuk akun masing-masing q9 = Peserta masuk akun masing masing

$\mathrm{q} 10=$ Peserta $\quad$ konfirmasi pembelajaran

$\mathrm{q} 11$ = Peserta pengambilan foto selfie $\mathrm{q} 12$ = Peserta menyetujui syarat dan ketentuan

q13 = Peserta mengerjakan soal pretest

q14 = Peserta mendapatkan modul pembelajaran

q15 = Peserta mengerjakan soal posttest

q16 = Peserta mendapatkan sertifikat pembelajaran 
Desain sistem digunakan untuk merancang sistem ini menggunakan diagram UML (Unified Modeling Language). UML adalah salah satu alat bantu yang sangat handal di dunia pengembangan sistem yang berorientasi objek (Munawar, 2018).

Use case diagram pada gambar 4 adalah proses pendaftaran karyawan dan proses pembelajaran pada aplikasi LMS sebagai berikut: 1) administrator membuat kelas, 2) administrator memilih soal pre-test, 3) administrator memilih modul kelas, 4) administrator meilih soal post-test, 5) administrator memilih jenis sertifikat, 6) administrator sinkornasi API data karyawan, 7) administrator mendaftarkan karyawan. Proses pembelajaran karyawan pada aplikasi LMS sebagai berikut: 1) karyawan konfirmasi pembelajaran melalui email, 2) karyawan masuk akun masing - masing, 3) karyawan melakukan swafoto, 4) karyawan menyetujui syarat dan ketentuan, 5) karyawan mengerjakan soal pre-test, 6) karyawan mendapatkan modul kelas, 7) karyawan mengerjakan post-test, 8) karyawan mendapatkan sertifikat.

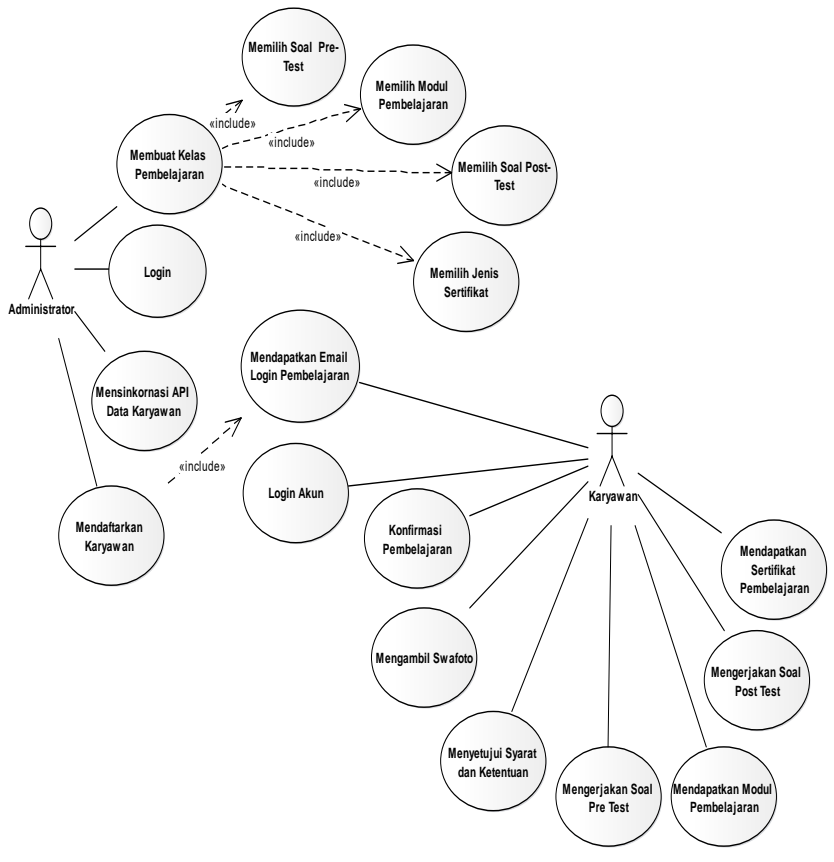

Gambar 4 Use Case Diagram LMS PT. Infomedia Nusantara
Sequence diagram admin aplikasi LMS dapat dilihat digambar 5 adalah proses pendaftaran karyawan dalam kelas pembelajaran mulai dari administrator membuat kelas, memilih soal pre-test, memilih modul pembelajaran, memilih soal post-test, memilih jenis sertifikat, mensinkornasi API data karyawan, mendaftarkan karyawan dalam kelas

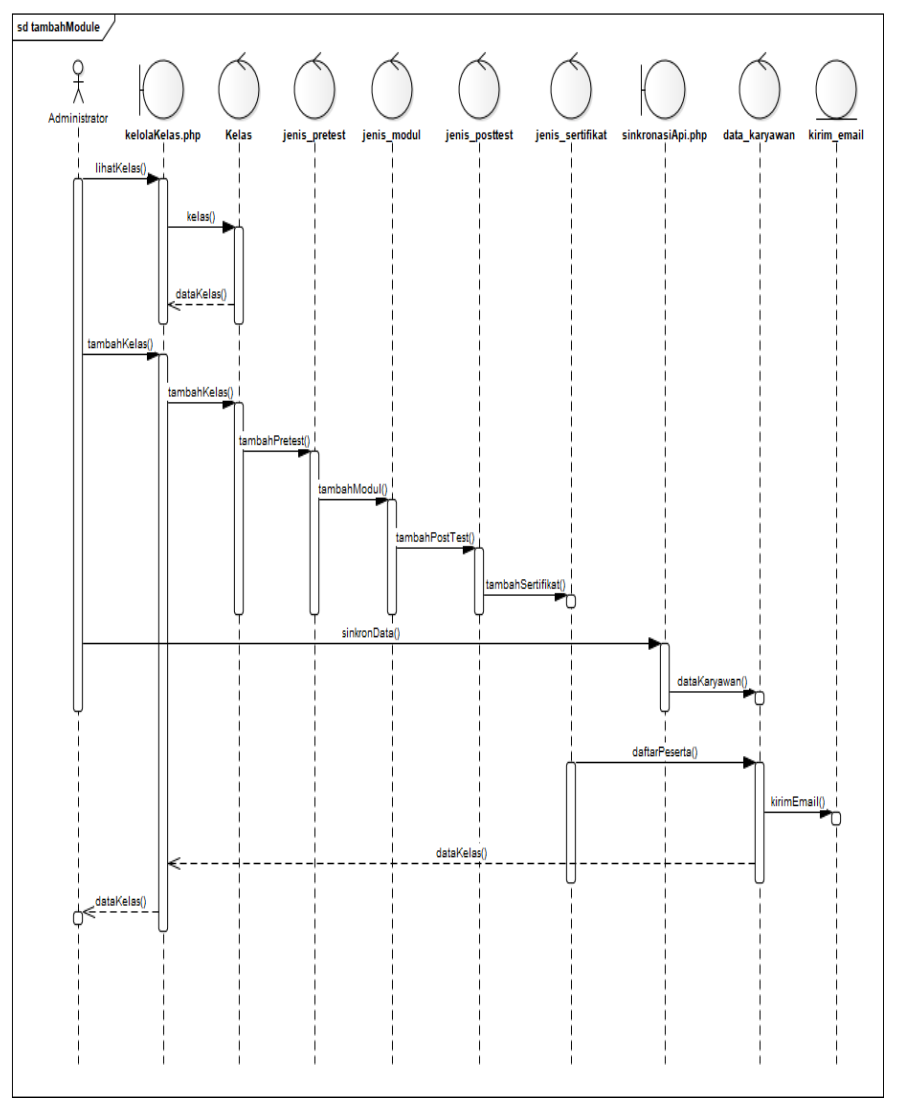

\section{Gambar 5 Sequence Diagram Admin} LMS PT. Infomedia Nusantara

Sequence diagram peserta atau karyawan pada aplikasi LMS dapat dilihat digambar 6 adalah proses peserta kelas pembelajaran tersebut, selanjutnya peserta akan diharuskan mengambil gambar swafoto sebelum mengikuti kelas,tahap berikutnya peserta akan menemui syarat dan ketentuan dalam kelas pembelajaran yang diikuti, tahap berikutnya peserta akan diberikan soal pretest, tahap berikutnya peserta akan diberikan 
module pembelajaran baik berupa gambar, presentasi, video, maupun hanya suara, selanjutnya karyawan mengerjakan soal post-test, dari tahap ini merupakan tahap terakhir dimana nilai akan dikalkulasi sesuai dengan pengerjaan tiap - tiap karyawan yang nantinya ada karyawan yang lulus kelas pembelajaran akan mendapatkan sertifikat kelulusan dari kelas yang dipelajarinya tersebut.

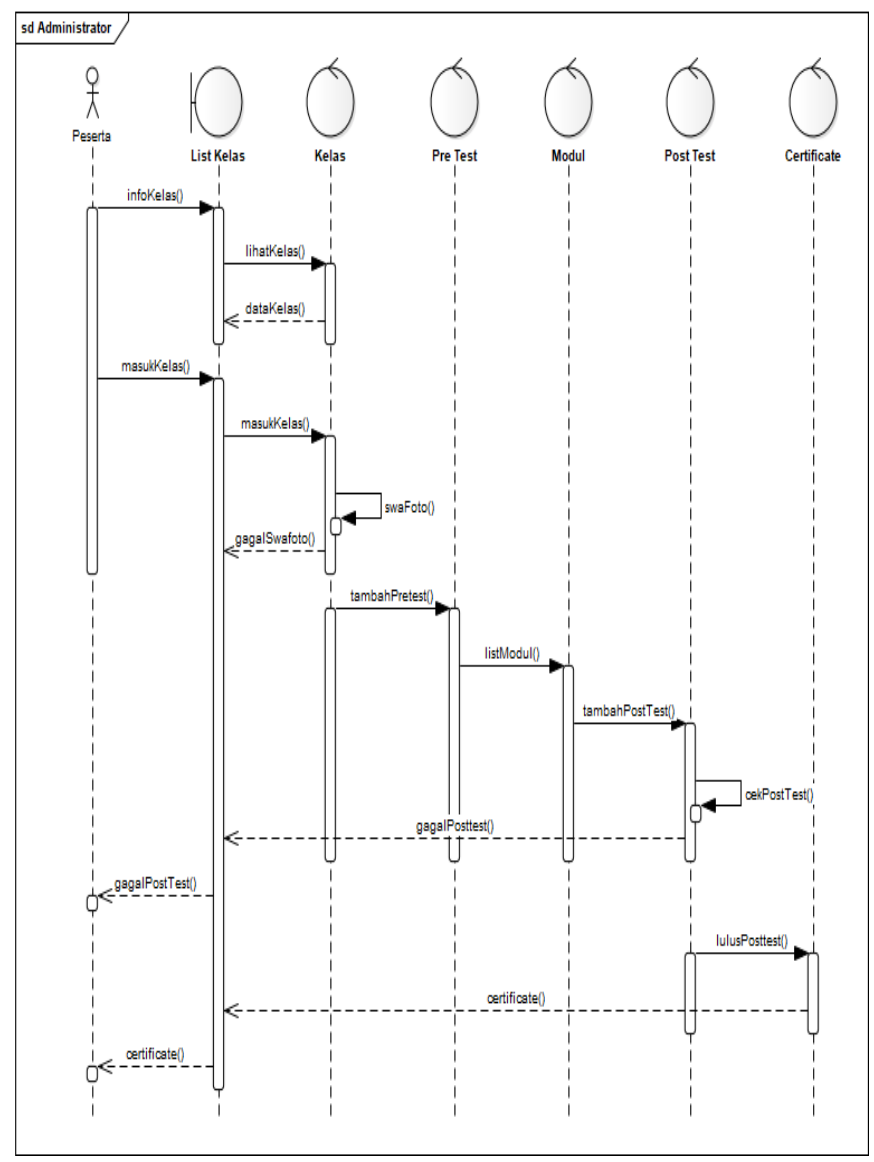

Gambar 6 Sequence Diagram peserta LMS PT. Infomedia Nusantara

Class diagram adalah suatu model sistem berbasis objek yang menjelaskan keterhubungan dalam sistem basis data yang mempunyai hubungan antar relasi tabel. Adapun pada aplikasi LMS dapat dilihat pada gambar 7.

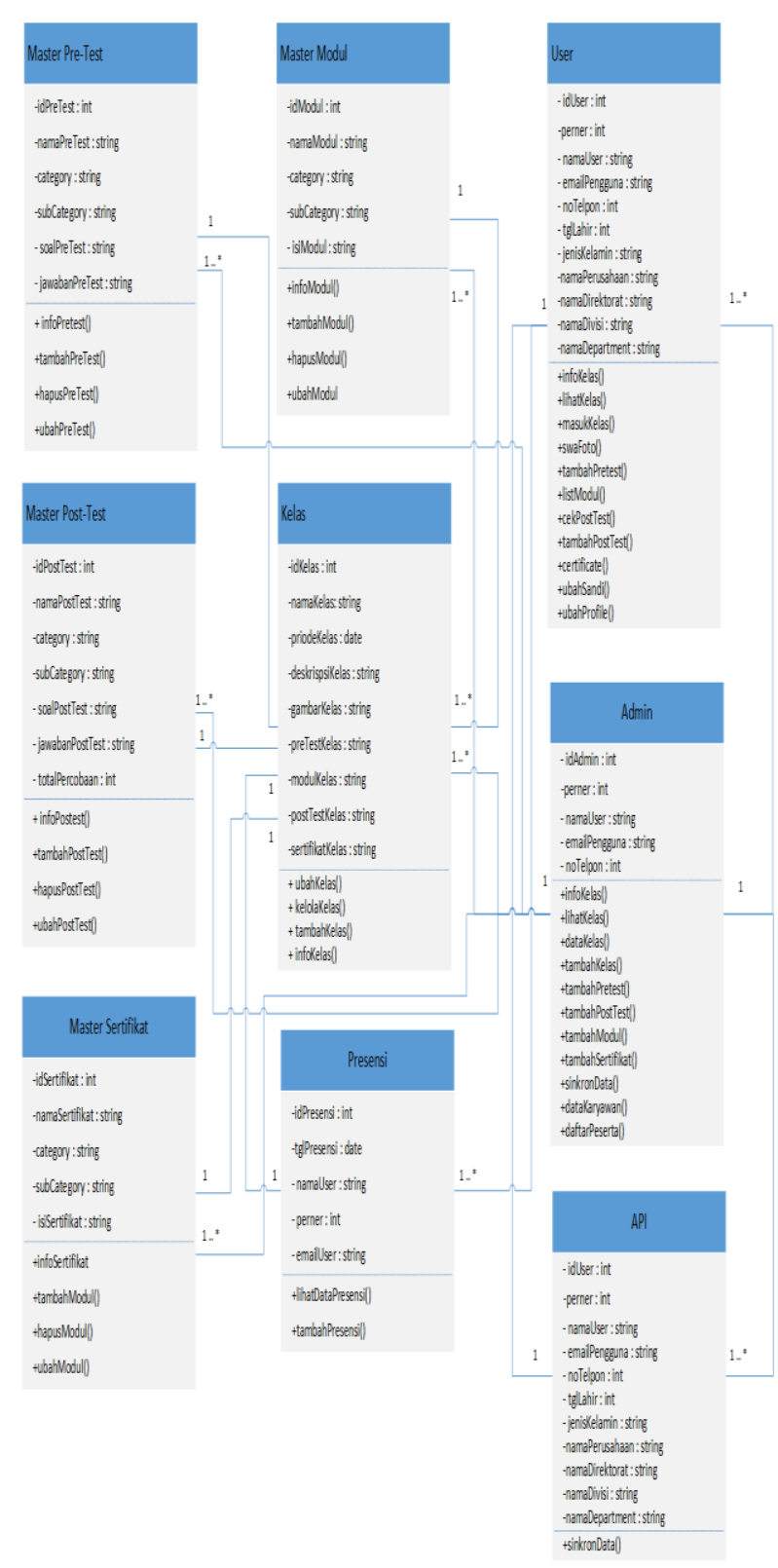

Gambar 7 Class Diagram LMS PT. Infomedia Nusantara

Activity diagram aplikasi LMS dapat dilihat digambar 8 adalah proses pendaftaran karyawan dalam kelas pembelajaran mulai dari administrator membuat kelas, memilih soal pre-test, memilih modul pembelajaran, memilih soal post-test, memilih jenis sertifikat, mensinkornasi API data karyawan, mendaftarkan karyawan dalam kelas. Selanjutnya karyawan mulai dari 
swafoto sampai dengan karyawan tersebut mendapatkan sertifikat pembelajaran.

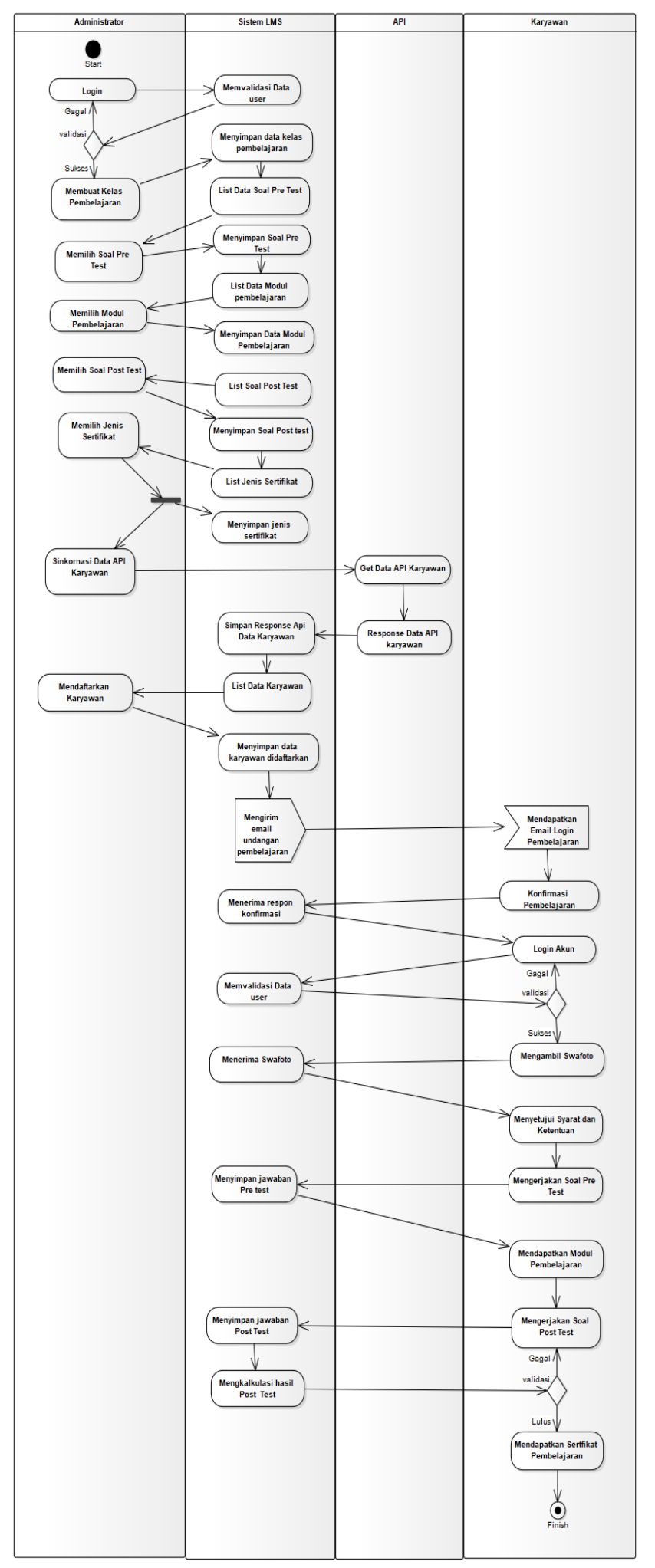

\section{Pembahasan}

Berdasarkan hasil dan Analisa sistem pada LMS PT. Infomedia Nusantara untuk penerapan sistem aplikasi ini dibutuhkan beberapa tahap diantaranya tahap pembuatan kelas, pendaftaran peserta, dan juga proses sinkronisasi data karyawan dengan API. Sistem REST Server disini sudah disediakan oleh perusahaan dibangun dengan bahasa pemrograman PHP sehingga dapat mudah diakses tanpa perlu membuat REST Server terlebih dahulu.

Untuk pembuatan kelas pada aplikasi LMS ini dibutuhkan masukan yang telah dinput oleh administrator mulai dari gambar, nama kelas, pretest, post-test, modul hingga sertifikat. Baris kode progam pembuatan kelas digambarkan pada gambar 9 .

if (\$_FILES["banner"]["name"] != "") \{

\$new_name $=\$$ coursecode. '_banner ' . time ()

\$config1['upload_path'] = './assets/backend/img/ ';

\$config1['allowed_types'] = 'jpg | png |jpeg|JPG|PNG|JPEG';

\$config1['file_name'] = \$new_name;

\$this->upload->initialize(\$config1);

if (\$this->upload->do_upload('banner')) \{

\$file img = \$this->upload->data('file name');

\} else \{

\$result = array("status" => "failed_extension", "reason" => strip_tags(u cfirst(\$this->upload->display_errors())) . ' In file Banner');

echo json_encode(\$result)

exit();

\}

$\$$ data $=$ array (

'img_file' => \$file_img,

'request code' $=>$ \$request code,

'course_id' => \$course_id,

'course_name_detail' $=>$ \$course_name_detail,

'vendor_id' => \$vendor_id,

'company_id' => \$company_id,

'pic_id' => \$pic_id,

'detail_course_type' => \$detail_course_type,

'is certified' $=>$ \$is_certified,

pre_test_id => \$pre_test_id,

post_test_id $=>$ \$post_test_id,

module id $\Rightarrow$ \$module id,

'detail_type_id' => \$detail_type_id,

'certificate_no' => \$certificate_number,

'certificate_increment_no' => \$certificate_increment_no,

\$data_save = call sp_create_course("'. \$data .'");

Gambar 8 Activity Diagram LMS PT. Infomedia Nusantara

Gambar 9 Kode membuat kelas 
Proses sinkronasi data karyawan, sebelum karyawan tersebut didaftarkan pada kelas pembelajaran data karyawan terlebih dahulu di sinkronisasi dengan API yang ada pada human resource. Dari pemanggilan API ini nantinya data yang dipanggil akan disimpan kedalam sistem basis data yang ada pada aplikasi LMS. Baris kode program pemanggilan digambarkan pada gambar 10.

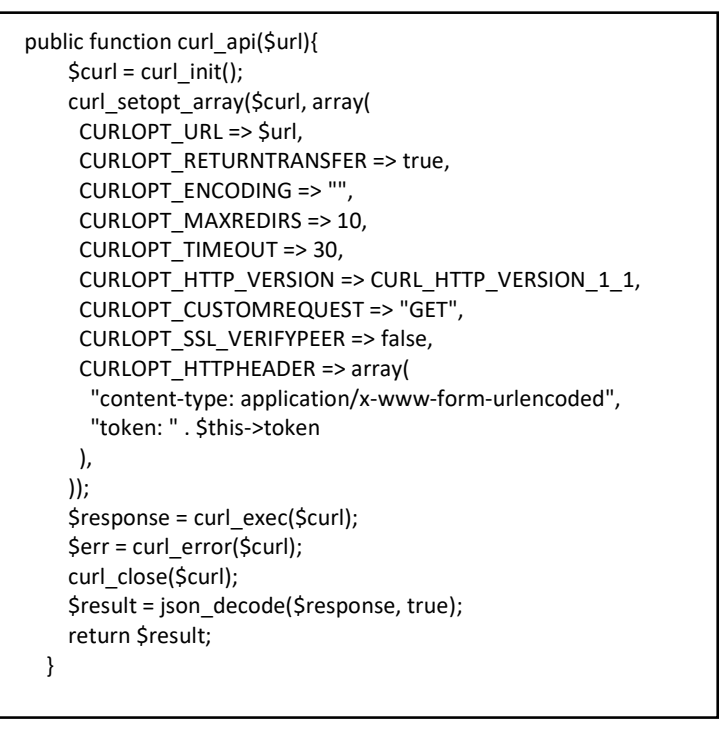

Gambar 10 Kode Pemanggilan API

Proses pendaftaran karyawan, setelah data karyawan didaptakan melalui API tahap selanjutnya adalah mendaftarakan peserta tersebut pada kelas pembelajaran. Baris kode program pendaftaran karyawan pada kelas pembelajaran digambarkan pada gambar 11.

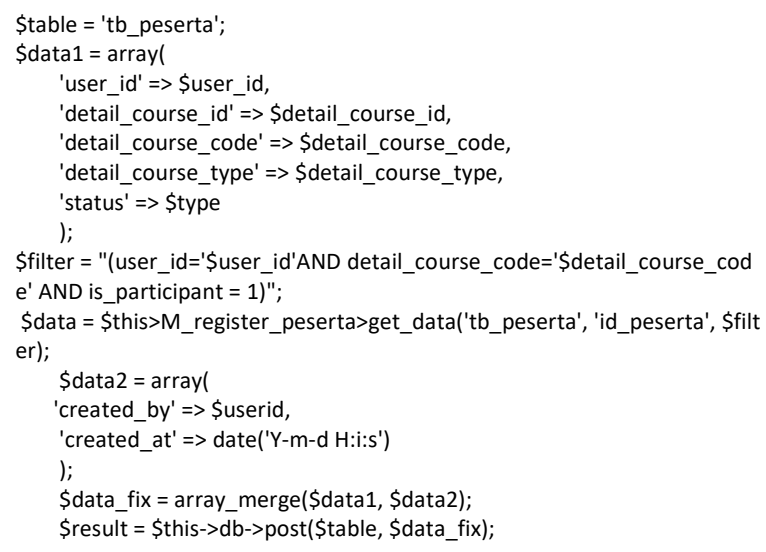

Gambar 11 Kode Pendaftaran Tahap selanjutnya adalah pengujian, pada tahap ini peserta didftarkan dalam suatu kelas pembelajaran menggunkanan data yang didapatkan dari API lalu disimpan pada sistem basis data LMS yang sudah di implementasikan pada tahap sebelumnya. Contoh pengujian ini digunakan data karyawan yang sebenarnya dan proses pengujian ini berjalan dengan sempurna dimana peserta tersebut berhasil mendapatkan email undangan kelas yang terdapat pada gambar 12 yang merupakan email yang didapatkan karyawan yang telah di undang training, karyawan mendapatkan email dan juga password yang dapat digunakan untuk mengakses training.
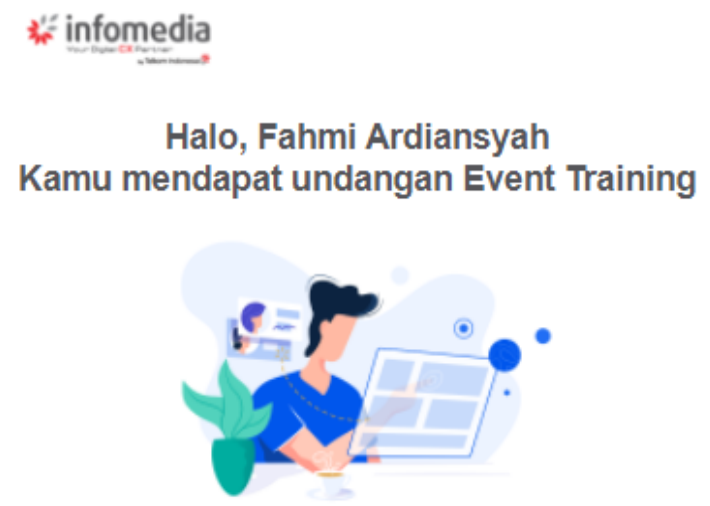

Selamat ya, sebagai / Learner ( Infomedia learner ) kamu memiliki kesempatan untuk upgrade kemampuan dan pengetahuan / Leamer dalam topik pembelajaran Customer Relationship Management ( Invira \& WhatsApp Business API ) ), apa saja upgrade yang didapat?

I Leamer akan belajar Mengenai Solusi PT Infomedia yaitu Invira \& WhatsApp For Business API.

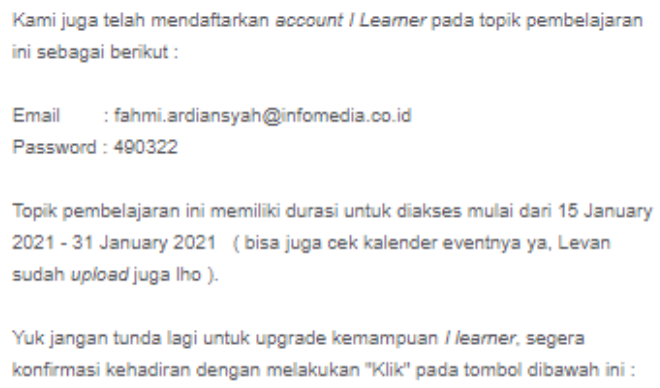


Gambar 12 Email undangan karyawan Pada gambar 13 merupakan desain dari form login digunakan sebagai validasi pengguna valid yang dapat mengakses LMS. Karyawan dapat mengakses website jika sudah memiliki email dan juga password yang telah diterima melalui email masing - masing karyawan yang dapat dilihat pada gambar 12 .

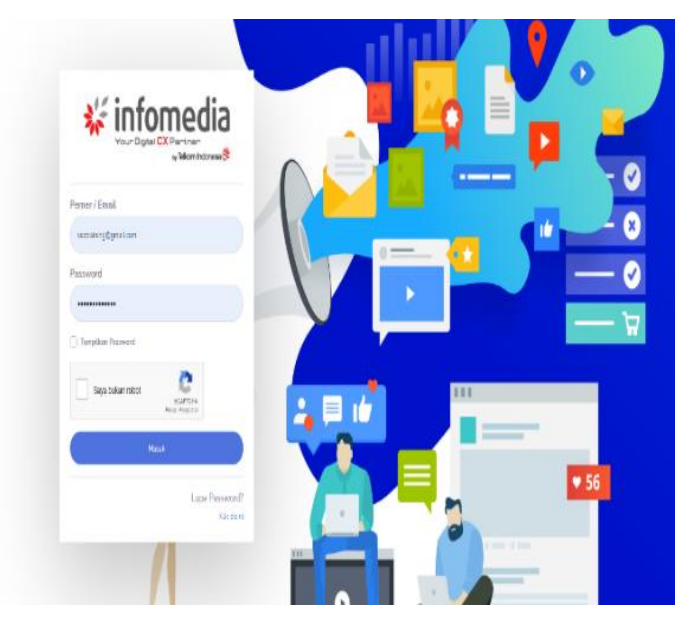

\section{Gambar 13 Form login}

Pada gambar 14 adalah halaman unduh sertifikat bagi karyawan yang telah menyelesaikan post-test sesuai dengan persyaratan dan ketentuan maka peserta tersebut berhak mendapatkan sertifikat.

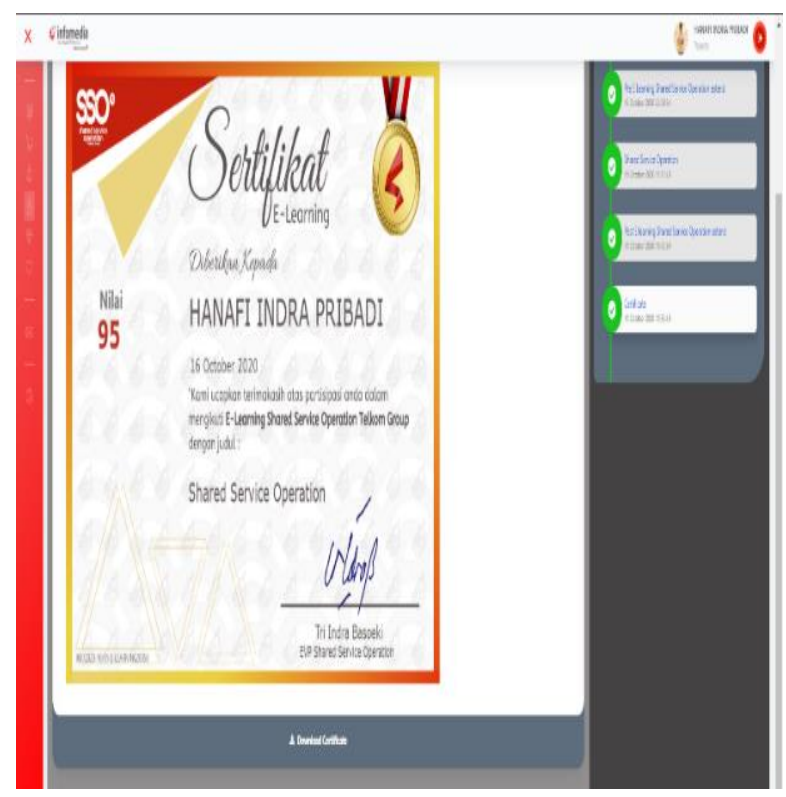

Gambar 14 Halaman unduh sertifikat Simpulan

Berdasarkan analisa, hasil dan pembahasan penelitian dapat mengambil kesimpulan aplikasi LMS ini dapat berjalan dengan sesuai dengan tujuan penelitian ini, model mesin turing ini dapat mempermudah dalam penerapan LMS pada PT. Infomedia Nusantara mulai dari proses pembuatan kelas, proses pendaftaran peserta dengan mengunakan API yang selanjutnya peserta mendapatkan pemberitahuan pendaftaran kelas melalui email yang terdaftar pada sistem basis data pada aplikasi yang diperoleh dari API, ada beberapa proses memerlukan waktu yang agak lama dalam pendaftaran data karyawan karena admin harus menyinkronisasi data terlebih dahulu agar data karyawan yang didaftarkan oleh admin selalu up to date.

Masih banyak yang dapat dikembangkan dari penelitian ini diantaranya, aplikasi ini belum mempunyai fitur Facial Recognition System (FRS), fitur ini sangat berguna dalam hal pengerjaan soal pre-test maupun post-test hal ini dilakukan agar dapat mengurangi kecurangan dalam pengerjaan soal. aplikasi ini harus menyediakan engine cronjob sehingga admin tidak perlu menyinkronisasi data setiap saat sehingga dapat lebih cepat dalam proses pembuatan kelas. Aplikasi ini belum mempunyai fitur notifikasi undangan kelas pembelajaran dengan menambahkan fitur undangan melalui pesan singkat whatsapp agar pemberitahuan dapat didapat secara cepat karna mayoritas sekarang ini karyawan lebih sering membuka pesan melalui whatsapp dibandingkan dengan email. 


\section{Referensi}

Affandi, L. (2018). Pencatatan Dan Pemisahan Data Log Proxy Server Ke Dalam Database Menggunakan Model Otomata Mesin Turing Di Stmik Ppkia Pradnya Paramita Malang Luqman Affandi *). Teknologi Informasi, 3(1), 32-42.

Affandi, L., Arhandi, P. P., \& Wibowo, D. W. (2019). Aplikasi Whatsapp Gateway Untuk Notifikasi Surat Peringatan Mahasiswa Menggunakan Metode Mesin Turing Dan Rest. Dinamika Dotcom, 10(Issn 2086-2652), 4958.

Aidah, S. (2019). Pemanfaatan ELearning Sebagai Media Pembelajaran Di Stia Al Gazali Barru (Suatu Studi Terhadap Pemanfaatan Model E-Learning Berbasis Software Claroline). Meraja Journal, 2(1), 1-12.

Donsu, J. (2017). Psikologi Keperawatan. Pustaka Baru Press.

Harijanto, B., P, D. K., \& Nova, B. P. (2017). Pengembangan Sistem Informasi Proses Belajar Mengajar Online Dengan Menggunakan Metode Pembelajaran Student Centered Learning (Scl). Jurnal Informatika Polinema, 4(1), 17. Https://Doi.Org/10.33795/Jip.V4i 1.139

Hidayat, R. (2017). Aplikasi Penjualan Jam Tangan Secara Online Studi Kasus: Toko Jamboreshop. Jurnal Teknik Komputer, Iii(2), 90-96.

Hidayatullah, P., \& Jauhari, K. K. (2017). Pemrograman Web (Revisi). Informatika.

Munawar, M. (2018). Analisis Perancangan Sistem Berorientasi Objek Dengan Uml. Informatika.

Nurmalasari, N., Anna, A., \& Arissusandi, R. (2019). Rancang Bangun Sistem Informasi Akuntansi Laporan Laba Rugi Berbasis Web. Jurnal Sains Dan Manajemen, 7(2), 6-14.
Risdiansyah, D. (2017). Perancangan Sistem Informasi Bimbingan Konseling Berbasis Desktop Pada Sma Kemala Bhayangkari 1 Kubu Raya Deni. Khatulistiwa Informatika, 5(2), 86-91. Https://Ejournal.Bsi.Ac.Id/Ejurnal /Index.Php/Khatulistiwa/Article/ View/2884

Rosa, A. S., \& Shalahuddin, M. (2018). Rekayasa Perangkat Lunak Terstruktur Dan Berorientasi Objek (Revisi). Informatika.

Sanova, A. (2018). Learning Management System (Lms) Sebagai Aplikasi Pengembangan Materi Interaktif Pokok Bahasan Daur Biogeokimia Berbasis Computer Assisted Instruction. Chempublish Journal, 3(1), 21-31. Https://Doi.Org/10.22437/Chp.V3 i1.5078

Setiyawan, A., Kusbianto, D., Aji, P., Ririd, A. R. T. H., Rohadi, E., \& Ananta, A. Y. (2019). Kiriman Pelanggan Mitra ( Studi Kasus Pada Kantor Pos Malang ). Jurnal Informatika Polinema, Vol.5(No.2), 101-107.

Siregar, F. H., Siregar, H. Y., \& Melani, M. (2018). Perancangan Aplikasi Komik Hadist Berbasis Multimedia. Jurti (Jurnal Teknologi Informasi), 2(2), 113121. Jurti (Jurnal Teknologi Informasi), 2(2), 113-121. Http://Www.Jurnal.Una.Ac.Id/Inde x.Php/Jurti/Article/View/425

Sulistyanto, H., \& Pulungan, R. (2014). Sebuah Review Singkat Terhadap Emulasi Cellular Automata Pada Mesin Turing. Komuniti, Vi(2), 142-154.

Yani, A., \& Saputra, B. (2018). Rancang Bangun Sistem Informasi Evaluasi Siswa Dan Kehadiran Guru Berbasis Web. Petir, 11(2). Https://Doi.Org/10.33322/Petir.V $11 \mathrm{i} 2.344$ 